\title{
On Asymptotically Lacunary Statistical Equivalent Set Sequences
}

\author{
Uğur Ulusu and Fatih Nuray \\ Department of Mathematics, Faculty of Science and Literature, Afyon Kocatepe University, 03200 Afyonkarahisar, Turkey
}

Correspondence should be addressed to Fatih Nuray; fnuray@aku.edu.tr

Received 12 November 2012; Accepted 23 January 2013

Academic Editor: Peijun Guo

Copyright (C) 2013 U. Ulusu and F. Nuray. This is an open access article distributed under the Creative Commons Attribution License, which permits unrestricted use, distribution, and reproduction in any medium, provided the original work is properly cited.

This paper presents three definitions which are natural combination of the definitions of asymptotic equivalence, statistical convergence, lacunary statistical convergence, and Wijsman convergence. In addition, we also present asymptotically equivalent (Wijsman sense) analogs of theorems in Patterson and Savaş (2006).

\section{Introduction}

In 1993, Marouf presented definitions for asymptotically equivalent and asymptotic regular matrices. In 2003, Patterson extended these concepts by presenting an asymptotically statistical equivalent analog of these definitions and natural regularity conditions for nonnegative summability matrices. In 2006, Patterson and Savaş extended the definitions presented in [1] to lacunary sequences. In addition to these definitions, natural inclusion theorems were presented. The concept of Wijsman statistical convergence is implementation of the concept of statistical convergence to sequences of sets presented by Nuray and Rhoades in 2012. Similar to this concept, the concept of Wijsman lacunary statistical convergence was presented by Ulusu and Nuray in 2012. This paper extends the definitions presented in [2] to Wijsman statistical convergent sequences and Wijsman lacunary statistical convergent sequences. In addition to these definitions, natural inclusion theorems will also be presented.

\section{Definitions and Notations}

Definition 1 (see Marouf [3]). Two nonnegative sequences $x=\left(x_{k}\right)$ and $y=\left(y_{k}\right)$ are said to be asymptotically equivalent if

$$
\lim _{k} \frac{x_{k}}{y_{k}}=1
$$

(denoted by $x \sim y$ ).
Definition 2 (see Fridy [4]). The sequence $x=\left(x_{k}\right)$ is said to be statistically convergent to the number $L$ if for every $\varepsilon>0$,

$$
\lim _{n} \frac{1}{n}\left|\left\{k \leq n:\left|x_{k}-L\right| \geq \varepsilon\right\}\right|=0 .
$$

In this case we write $s t-\lim x_{k}=L$.

The next definition is natural combination of Definitions 1 and 2 .

Definition 3 (see Patterson [1]). Two nonnegative sequences $x=\left(x_{k}\right)$ and $y=\left(y_{k}\right)$ are said to be asymptotically statistical equivalent of multiple $L$ provided that for every $\varepsilon>0$

$$
\lim _{n} \frac{1}{n}\left|\left\{k \leq n:\left|\frac{x_{k}}{y_{k}}-L\right| \geq \varepsilon\right\}\right|=0
$$

(denoted by $x \stackrel{S_{L}}{\sim} y$ ) and simply asymptotically statistically equivalent if $L=1$.

By a lacunary sequence we mean an increasing integer sequence $\theta=\left\{k_{r}\right\}$ such that $k_{0}=0$ and $h_{r}=k_{r}-k_{r-1} \rightarrow \infty$ as $r \rightarrow \infty$. Throughout this paper the intervals determined by $\theta$ will be denoted by $I_{r}=\left(k_{r-1}, k_{r}\right]$, and ratio $k_{r} / k_{r-1}$ will be abbreviated by $q_{r}$.

Definition 4 (see Patterson and Savaş [2]). Let $\theta$ be a lacunary sequence; the two nonnegative sequences $x=\left(x_{k}\right)$ and 
$y=\left(y_{k}\right)$ are said to be asymptotically lacunary statistical equivalent of multiple $L$ provided that for every $\varepsilon>0$

$$
\lim _{r} \frac{1}{h_{r}}\left|\left\{k \in I_{r}:\left|\frac{x_{k}}{y_{k}}-L\right| \geq \varepsilon\right\}\right|=0
$$

(denoted by $x \stackrel{S_{\theta}^{L}}{\sim} y$ ) and simply asymptotically lacunary statistically equivalent if $L=1$.

Definition 5 (see Patterson \& Savaş [2]). Let $\theta$ be a lacunary sequence; two nonnegative number sequences $x=\left(x_{k}\right)$ and $y=\left(y_{k}\right)$ are strongly asymptotically lacunary equivalent of multiple $L$ provided that

$$
\lim _{r} \frac{1}{h_{r}} \sum_{k \in I_{r}}\left|\frac{x_{k}}{y_{k}}-L\right|=0
$$

(denoted by $x \stackrel{N_{\theta}^{L}}{\sim} y$ ) and strongly simply asymptotically lacunary equivalent if $L=1$.

Let $(X, \rho)$ be a metric space. For any point $x \in X$ and any nonempty subset $A$ of $X$, we define the distance from $x$ to $A$ by

$$
d(x, A)=\inf _{a \in A} \rho(x, A)
$$

Definition 6 (see Baronti \& Papini [5]). Let $(X, \rho)$ be a metric space. For any nonempty closed subset $A, A_{k} \subseteq X$, we say that the sequence $\left\{A_{k}\right\}$ is Wijsman convergent to $A$ if

$$
\lim _{k \rightarrow \infty} d\left(x, A_{k}\right)=d(x, A)
$$

for each $x \in X$. In this case we write $W-\lim A_{k}=A$.

Definition 7 (see Nuray \& Rhoades [6]). Let $(X, \rho)$ a metric space. For any nonempty closed subset $A, A_{k} \subseteq X$, we say that the sequence $\left\{A_{k}\right\}$ is Wijsman statistically convergent to $A$ if $\left\{d\left(x, A_{k}\right)\right\}$ is statistically convergent to $d(x, A)$; that is, for $\varepsilon>0$ and for each $x \in X$,

$$
\lim _{n \rightarrow \infty} \frac{1}{n}\left|\left\{k \leq n:\left|d\left(x, A_{k}\right)-d(x, A)\right| \geq \varepsilon\right\}\right|=0 .
$$

In this case we write $s t-\lim _{W} A_{k}=A$ or $A_{k} \rightarrow A(W S)$.

Also the concept of bounded sequence for sequences of sets was given by Nuray and Rhoades.

Definition 8 (see Nuray \& Rhoades $[6])$. Let $(X, \rho)$ be a metric space. For any nonempty closed subset $A_{k}$ of $X$, we say that the sequence $\left\{A_{k}\right\}$ is bounded if

$$
\sup _{k} d\left(x, A_{k}\right)<\infty
$$

for each $x \in X$. In this case we write $\left\{A_{k}\right\} \in L_{\infty}$.

Definition 9 (see Ulusu \& Nuray [7]). Let $(X, \rho)$ be a metric space and let $\theta=\left\{k_{r}\right\}$ be a lacunary sequence. For any nonempty closed subset $A, A_{k} \subseteq X$, we say that the sequence
$\left\{A_{k}\right\}$ is Wijsman lacunarily statistically convergent to $A$ if $\left\{d\left(x, A_{k}\right)\right\}$ is lacunarily statistically convergent to $d(x, A)$; that is, for $\varepsilon>0$ and for each $x \in X$,

$$
\lim _{r} \frac{1}{h_{r}}\left|\left\{k \in I_{r}:\left|d\left(x, A_{k}\right)-d(x, A)\right| \geq \varepsilon\right\}\right|=0 .
$$

In this case we write $S_{\theta}-\lim _{W}=A$ or $A_{k} \rightarrow A\left(W S_{\theta}\right)$.

Following these results we introduce three new notions that are asymptotically statistical equivalent (Wijsman sense) of multiple $L$, asymptotically lacunary statistical equivalent (Wijsman sense) of multiple $L$, and strongly asymptotically lacunary equivalent (Wijsman sense) of multiple $L$.

Definition 10. Let $(X, \rho)$ be a metric space. For any nonempty closed subset $A_{k}, B_{k} \subseteq X$ such that $d\left(x, A_{k}\right)>0$ and $d\left(x, B_{k}\right)>0$ for each $x \in X$. We say that the sequences $\left\{A_{k}\right\}$ and $\left\{B_{k}\right\}$ are asymptotically equivalent (Wijsman sense) if for each $x \in X$,

$$
\lim _{k} \frac{d\left(x, A_{k}\right)}{d\left(x, B_{k}\right)}=1
$$

(denoted by $A_{k} \sim B_{k}$ ).

As an example, consider the following sequences of circles in the $(x, y)$-plane:

$$
\begin{aligned}
& A_{k}=\left\{(x, y): x^{2}+y^{2}+2 k x=0\right\}, \\
& B_{k}=\left\{(x, y): x^{2}+y^{2}-2 k x=0\right\} .
\end{aligned}
$$

Since

$$
\lim _{k} \frac{d\left(x, A_{k}\right)}{d\left(x, B_{k}\right)}=1
$$

the sequences $\left\{A_{k}\right\}$ and $\left\{B_{k}\right\}$ are asymptotically equivalent (Wijsman sense); that is, $A_{k} \sim B_{k}$.

Definition 11. Let $(X, \rho)$ be a metric space. For any non-empty closed subset $A_{k}, B_{k} \subseteq X$ such that $d\left(x, A_{k}\right)>0$ and $d\left(x, B_{k}\right)>0$ for each $x \in X$. We say that the sequences $\left\{A_{k}\right\}$ and $\left\{B_{k}\right\}$ are asymptotically statistically equivalent (Wijsman sense) of multiple $L$ if for every $\varepsilon>0$ and for each $x \in X$,

$$
\lim _{n} \frac{1}{n}\left|\left\{k \leq n:\left|\frac{d\left(x, A_{k}\right)}{d\left(x, B_{k}\right)}-L\right| \geq \varepsilon\right\}\right|=0
$$

(denoted by $\left\{A_{k}\right\} \stackrel{W S_{L}}{\sim}\left\{B_{k}\right\}$ ) and simply asymptotically statistical equivalent (Wijsman sense) if $L=1$. 
As an example, consider the following sequences of circles in the $(x, y)$-plane:

$$
\begin{gathered}
A_{k}=\left\{\begin{array}{r}
\left\{(x, y): x^{2}+y^{2}+2 k y=0\right\}, \\
\text { if } k \text { is a square integer, } \\
\{(1,1)\},
\end{array}\right. \\
B_{k}=\left\{\begin{array}{cc}
\left\{(x, y): x^{2}+y^{2}-2 k y=0\right\}, \\
\text { otherwise, } k \text { is a square integer, } \\
\{(1,1)\}, & \text { otherwise. }
\end{array}\right.
\end{gathered}
$$

Since

$$
\lim _{n} \frac{1}{n}\left|\left\{k \leq n:\left|\frac{d\left(x, A_{k}\right)}{d\left(x, B_{k}\right)}-1\right| \geq \varepsilon\right\}\right|=0,
$$

the sequences $\left\{A_{k}\right\}$ and $\left\{B_{k}\right\}$ are asymptotically statistically equivalent (Wijsman sense); that is, $\left\{A_{k}\right\} \stackrel{W S_{1}}{\sim}\left\{B_{k}\right\}$.

Definition 12. Let $(X, \rho)$ be a metric space and let $\theta$ be a lacunary sequence. For any non-empty closed subset $A_{k}$, $B_{k} \subseteq X$ such that $d\left(x, A_{k}\right)>0$ and $d\left(x, B_{k}\right)>0$ for each $x \in$ $X$. We say that the sequences $\left\{A_{k}\right\}$ and $\left\{B_{k}\right\}$ are asymptotically lacunary equivalent (Wijsman sense) of multiple $L$ if for each $x \in X$,

$$
\lim _{r} \frac{1}{h_{r}} \sum_{k \in I_{r}} \frac{d\left(x, A_{k}\right)}{d\left(x, B_{k}\right)}=L
$$

(denoted by $\left\{A_{k}\right\} \stackrel{W N_{\theta}^{L}}{\sim}\left\{B_{k}\right\}$ ) and simply asymptotically lacunarily equivalent (Wijsman sense) if $L=1$.

Definition 13. Let $(X, \rho)$ be a metric space and let $\theta$ be a lacunary sequence. For any non-empty closed subset $A_{k}$, $B_{k} \subseteq X$ such that $d\left(x, A_{k}\right)>0$ and $d\left(x, B_{k}\right)>0$ for each $x \in X$. We say that the sequences $\left\{A_{k}\right\}$ and $\left\{B_{k}\right\}$ are strongly asymptotically lacunary equivalent (Wijsman sense) of multiple $L$ if for each $x \in X$,

$$
\lim _{r} \frac{1}{h_{r}} \sum_{k \in I_{r}}\left|\frac{d\left(x, A_{k}\right)}{d\left(x, B_{k}\right)}-L\right|=0
$$

(denoted by $\left\{A_{k}\right\} \stackrel{[W N]_{\theta}^{L}}{\sim}\left\{B_{k}\right\}$ ) and simply strongly asymptotically lacunarily equivalent (Wijsman sense) if $L=1$.

As an example, consider the following sequences:

$$
\begin{aligned}
& A_{k}:=\left\{\begin{array}{lr}
\left\{(x, y) \in \mathbb{R}^{2}: \frac{(x-\sqrt{k})^{2}}{k}+\frac{y^{2}}{2 k}=1\right\}, \\
\{(1,1)\}, & \text { if } k_{r-1}<k<k_{r-1}+\left[\sqrt{h_{r}}\right]
\end{array}\right. \\
& B_{k}:=\left\{\begin{array}{rr}
\left\{(x, y) \in \mathbb{R}^{2}: \frac{(x+\sqrt{k})^{2}}{k}+\frac{y^{2}}{2 k}=1\right\}, \\
\{(1,1)\}, & \text { if } k_{r-1}<k<k_{r-1}+\left[\sqrt{h_{r}}\right]
\end{array}\right. \\
& \text { otherwise, }
\end{aligned}
$$

Since

$$
\lim _{r} \frac{1}{h_{r}} \sum_{k \in I_{r}}\left|\frac{d\left(x, A_{k}\right)}{d\left(x, B_{k}\right)}-1\right|=0,
$$

the sequences $\left\{A_{k}\right\}$ and $\left\{B_{k}\right\}$ are strongly asymptotically lacunarily equivalent (Wijsman sense); that is, $\left\{A_{k}\right\} \stackrel{W N_{\theta}^{1}}{\sim}$ $\left\{B_{k}\right\}$.

Definition 14. Let $(X, \rho)$ be a metric space and let $\theta$ be a lacunary sequence. For any non-empty closed subset $A_{k}, B_{k} \subseteq X$ such that $d\left(x, A_{k}\right)>0$ and $d\left(x, B_{k}\right)>0$ for each $x \in X$. We say that the sequences $\left\{A_{k}\right\}$ and $\left\{B_{k}\right\}$ are asymptotically lacunarily statistical equivalent (Wijsman sense) of multiple $L$ if for every $\varepsilon>0$ and each $x \in X$,

$$
\lim _{r} \frac{1}{h_{r}}\left|\left\{k \in I_{r}:\left|\frac{d\left(x, A_{k}\right)}{d\left(x, B_{k}\right)}-L\right| \geq \varepsilon\right\}\right|=0
$$

(denoted by $\left\{A_{k}\right\} \stackrel{W S_{\theta}^{L}}{\sim}\left\{B_{k}\right\}$ ) and simply asymptotically lacunarily statistically equivalent (Wijsman sense) if $L=1$.

As an example, consider the following sequences:

$$
\begin{aligned}
& A_{k}:=\left\{\begin{array}{rr}
\left\{(x, y) \in \mathbb{R}^{2}: x^{2}+(y-1)^{2}=\frac{1}{k}\right\} & \begin{array}{r}
\text { if } k_{r-1}<k<k_{r-1}+\left[\sqrt{h_{r}}\right], \\
k \text { is a square integer, }
\end{array} \\
\{(0,0)\}, & \text { otherwise, }
\end{array}\right. \\
& B_{k}:=\left\{\begin{array}{rr}
\left\{(x, y) \in \mathbb{R}^{2}: x^{2}+(y+1)^{2}=\frac{1}{k}\right\} \\
\text { if } k_{r-1}<k<k_{r-1}+\left[\sqrt{h_{r}}\right], \\
k(0,0)\}, & \text { otherwise. }
\end{array}\right.
\end{aligned}
$$

Since

$$
\lim _{r} \frac{1}{h_{r}}\left|\left\{k \in I_{r}:\left|\frac{d\left(x, A_{k}\right)}{d\left(x, B_{k}\right)}-1\right| \geq \varepsilon\right\}\right|=0,
$$

the sequences $\left\{A_{k}\right\}$ and $\left\{B_{k}\right\}$ are asymptotically lacunarily statistically equivalent (Wijsman sense); that is, $\left\{A_{k}\right\} \stackrel{W S_{\theta}^{1}}{\sim}$ $\left\{B_{k}\right\}$.

\section{Main Results}

Theorem 15. Let $(X, \rho)$ be a metric space, let $\theta=\left\{k_{r}\right\}$ be a lacunary sequence, and let $A_{k}, B_{k}$ be non-empty closed subsets of $X$ :
(i) (a) $\left\{A_{k}\right\} \stackrel{[W N]_{\theta}^{L}}{\sim}\left\{B_{k}\right\} \Rightarrow\left\{A_{k}\right\} \stackrel{W S_{\theta}^{L}}{\sim}\left\{B_{k}\right\}$
(b) $[W N]_{\theta}^{L}$ is a proper subset of $W S_{\theta}^{L}$, 
(ii) $\left\{A_{k}\right\} \in L_{\infty}$ and $\left\{A_{k}\right\} \stackrel{W S_{\theta}^{L}}{\sim}\left\{B_{k}\right\} \Rightarrow\left\{A_{k}\right\} \stackrel{[W N]_{\theta}^{L}}{\sim}\left\{B_{k}\right\}$,

(iii) $W S_{\theta}^{L} \cap L_{\infty}=[W N]_{\theta}^{L} \cap L_{\infty}$,

where $L_{\infty}$ denotes the set of bounded sequences of sets.

Proof. (i)-(a). Let $\varepsilon>0$ and $\left\{A_{k}\right\} \stackrel{[W N]_{\theta}^{L}}{\sim}\left\{B_{k}\right\}$. Then we can write

$$
\begin{array}{r}
\sum_{k \in I_{r}}\left|\frac{d\left(x, A_{k}\right)}{d\left(x, B_{k}\right)}-L\right| \\
\geq \sum_{k \in I_{r}}\left|\frac{d\left(x, A_{k}\right)}{d\left(x, B_{k}\right)}-L\right| \\
\quad \geq \varepsilon \cdot\left|d\left(x, A_{k}\right) / d\left(x, B_{k}\right)-L\right| \geq \varepsilon \\
\end{array}
$$

which yields the result.

(ii)-(b). Suppose that $[W N]_{\theta}^{L} \subset W S_{\theta}^{L}$. Let $\left\{A_{k}\right\}$ and $\left\{B_{k}\right\}$ be the following sequences:

$$
\begin{aligned}
& A_{k}=\left\{\begin{array}{rr}
\{k\}, & \text { if } k_{r-1}<k \leq k_{r-1}+\left[\sqrt{h_{r}}\right] \\
\{0\}, & r=1,2, \ldots
\end{array}\right. \\
& B_{k}=\{0\} \quad \forall k .
\end{aligned}
$$

Note that $\left\{A_{k}\right\}$ is not bounded. We have, for every $\varepsilon>0$ and for each $x \in X$,

$$
\begin{array}{r}
\frac{1}{h_{r}}\left|\left\{k \in I_{r}:\left|\frac{d\left(x, A_{k}\right)}{d\left(x, B_{k}\right)}-1\right| \geq \varepsilon\right\}\right|=\frac{\left[\sqrt{h_{r}}\right]}{h_{r}} \longrightarrow 0 \\
\text { as } r \longrightarrow \infty .
\end{array}
$$

That is, $\left\{A_{k}\right\} \stackrel{W S_{\theta}^{1}}{\sim}\left\{B_{k}\right\}$. On the other hand,

$$
\frac{1}{h_{r}} \sum_{k \in I_{r}}\left|\frac{d\left(x, A_{k}\right)}{d\left(x, B_{k}\right)}-L\right| \nrightarrow 0 \quad \text { as } r \longrightarrow \infty
$$

Hence $\left\{A_{k}\right\} \stackrel{[W N]_{\theta}^{L}}{*}\left\{B_{k}\right\}$.

(ii) Suppose that $\left\{A_{k}\right\} \in L_{\infty}$ and $\left\{A_{k}\right\} \stackrel{W s_{\theta}^{L}}{\sim}\left\{B_{k}\right\}$. Then we can assume that

$$
\left|\frac{d\left(x, A_{k}\right)}{d\left(x, B_{k}\right)}-L\right| \leq M
$$

for each $x \in X$ and all $k$.
Given $\varepsilon>0$, we get

$$
\begin{aligned}
\frac{1}{h_{r}} \sum_{k \in I_{r}}\left|\frac{d\left(x, A_{k}\right)}{d\left(x, B_{k}\right)}-L\right| & \frac{1}{h_{r}} \sum_{k \in I_{r}}\left|\frac{d\left(x, A_{k}\right)}{d\left(x, B_{k}\right)}-L\right| \\
& +\frac{1}{h_{r}} \sum_{k \in I_{r}}\left|\frac{d\left(x, A_{k}\right)}{d\left(x, B_{k}\right)}-L\right| \\
\leq & \frac{M}{h_{r}} \mid\left\{k \in I_{k}: d\left(x, B_{k}\right)-L \mid \geq \varepsilon\right. \\
\left|d\left(x, A_{k}\right) / d\left(x, B_{k}\right)-L\right|<\varepsilon & \left.\left|\frac{d\left(x, A_{k}\right)}{d\left(x, B_{k}\right)}-L\right| \geq \varepsilon\right\} \mid+\varepsilon .
\end{aligned}
$$

Therefore $\left\{A_{k}\right\} \stackrel{[W N]_{\theta}^{L}}{\sim}\left\{B_{k}\right\}$.

(iii) This is an immediate consequences of (i)and (ii).

Theorem 16. Let $(X, \rho)$ be a metric space and let $A_{k}, B_{k}$ be non-empty closed subsets of $X$. If $\theta=\left\{k_{r}\right\}$ is a lacunary sequence with $\lim \inf _{r} q_{r}>1$, then

$$
\left\{A_{k}\right\} \stackrel{W S_{L}}{\sim}\left\{B_{k}\right\} \Longrightarrow\left\{A_{k}\right\} \stackrel{W S_{\theta}^{L}}{\sim}\left\{B_{k}\right\}
$$

Proof. Suppose first that $\lim \inf _{r} q_{r}>1$, then there exists a $\lambda>0$ such that $q_{r} \geq 1+\lambda$ for sufficiently large $r$, which implies that

$$
\frac{h_{r}}{k_{r}} \geq \frac{\lambda}{1+\lambda}
$$

If $\left\{A_{k}\right\} \stackrel{W S_{L}}{\sim}\left\{B_{k}\right\}$, then for every $\varepsilon>0$, for each $x \in X$, and for sufficiently large $r$, we have

$$
\begin{aligned}
& \frac{1}{k_{r}}\left|\left\{k \leq k_{r}:\left|\frac{d\left(x, A_{k}\right)}{d\left(x, B_{k}\right)}-L\right| \geq \varepsilon\right\}\right| \\
& \quad \geq \frac{1}{k_{r}}\left|\left\{k \in I_{r}:\left|\frac{d\left(x, A_{k}\right)}{d\left(x, B_{k}\right)}-L\right| \geq \varepsilon\right\}\right| \\
& \quad \geq \frac{\lambda}{1+\lambda} \cdot\left(\frac{1}{h_{r}}\left|\left\{k \in I_{r}:\left|\frac{d\left(x, A_{k}\right)}{d\left(x, B_{k}\right)}-L\right| \geq \varepsilon\right\}\right|\right) .
\end{aligned}
$$

This completes the proof.

Theorem 17. Let $(X, \rho)$ be a metric space and let $A_{k}, B_{k}$ be non-empty closed subsets of $X$. If $\theta=\left\{k_{r}\right\}$ is a lacunary sequence with $\lim \sup _{r} q_{r}<\infty$, then

$$
\left\{A_{k}\right\} \stackrel{W S_{\theta}^{L}}{\sim}\left\{B_{k}\right\} \Longrightarrow\left\{A_{k}\right\} \stackrel{W S_{L}}{\sim}\left\{B_{k}\right\} .
$$

Proof. Let $\lim \sup _{r} q_{r}<\infty$. Then there is an $M>0$ such that $q_{r}<M$ for all $r \geq 1$. Let $\left\{A_{k}\right\} \stackrel{W S_{\theta}^{L}}{\sim}\left\{B_{k}\right\}$ and $\varepsilon>0$. There exists $R>0$ such that for every $j \geq R$

$$
A_{j}=\frac{1}{h_{j}}\left|\left\{k \in I_{j}:\left|\frac{d\left(x, A_{k}\right)}{d\left(x, B_{k}\right)}-L\right| \geq \varepsilon\right\}\right|<\varepsilon .
$$


We can also find $H>0$ such that $A_{j}<H$ for all $j=1,2, \ldots$. Now let $t$ be any integer satisfying $k_{r-1}<t \leq k_{r}$, where $r>R$.

Then we can write

$$
\begin{aligned}
& \frac{1}{t}\left|\left\{k \leq t:\left|\frac{d\left(x, A_{k}\right)}{d\left(x, B_{k}\right)}-L\right| \geq \varepsilon\right\}\right| \\
& \leq \frac{1}{k_{r-1}}\left|\left\{k \leq k_{r}:\left|\frac{d\left(x, A_{k}\right)}{d\left(x, B_{k}\right)}-L\right| \geq \varepsilon\right\}\right| \\
& =\frac{1}{k_{r-1}}\left\{\left|\left\{k \in I_{1}:\left|\frac{d\left(x, A_{k}\right)}{d\left(x, B_{k}\right)}-L\right| \geq \varepsilon\right\}\right|\right\} \\
& +\frac{1}{k_{r-1}}\left\{\left|\left\{k \in I_{2}:\left|\frac{d\left(x, A_{k}\right)}{d\left(x, B_{k}\right)}-L\right| \geq \varepsilon\right\}\right|\right\} \\
& +\cdots+\frac{1}{k_{r-1}} \\
& \times\left\{\left|\left\{k \in I_{r}:\left|\frac{d\left(x, A_{k}\right)}{d\left(x, B_{k}\right)}-L\right| \geq \varepsilon\right\}\right|\right\} \\
& =\frac{k_{1}}{k_{r-1} k_{1}}\left|\left\{k \in I_{1}:\left|\frac{d\left(x, A_{k}\right)}{d\left(x, B_{k}\right)}-L\right| \geq \varepsilon\right\}\right| \\
& +\frac{k_{2}-k_{1}}{k_{r-1}\left(k_{2}-k_{1}\right)} \\
& \times\left|\left\{k \in I_{2}:\left|\frac{d\left(x, A_{k}\right)}{d\left(x, B_{k}\right)}-L\right| \geq \varepsilon\right\}\right| \\
& +\cdots+\frac{k_{R}-k_{R-1}}{k_{r-1}\left(k_{R}-k_{R-1}\right)} \\
& \times\left|\left\{k \in I_{R}:\left|\frac{d\left(x, A_{k}\right)}{d\left(x, B_{k}\right)}-L\right| \geq \varepsilon\right\}\right| \\
& +\cdots+\frac{k_{r}-k_{r-1}}{k_{r-1}\left(k_{r}-k_{r-1}\right)} \\
& \times\left|\left\{k \in I_{r}:\left|\frac{d\left(x, A_{k}\right)}{d\left(x, B_{k}\right)}-L\right| \geq \varepsilon\right\}\right| \\
& =\frac{k_{1}}{k_{r-1}} A_{1}+\frac{k_{2}-k_{1}}{k_{r-1}} A_{2}+\cdots+\frac{k_{R}-k_{R-1}}{k_{r-1}} A_{R} \\
& +\frac{k_{R+1}-k_{R}}{k_{r-1}} A_{R+1}+\cdots+\frac{k_{r}-k_{r-1}}{k_{r-1}} A_{r} \\
& \leq\left\{\sup _{j \geq 1} A_{j}\right\} \frac{k_{R}}{k_{r-1}}+\left\{\sup _{j \geq B} A_{j}\right\} \frac{k_{r}-k_{R}}{k_{r-1}} \\
& \leq H \frac{k_{B}}{k_{r-1}}+\varepsilon M .
\end{aligned}
$$

Theorem 18. Let $(X, \rho)$ be a metric space and let $A_{k}, B_{k}$ be non-empty closed subsets of $X$. If $\theta=\left\{k_{r}\right\}$ is a lacunary sequence with $1<\liminf _{r} q_{r} \leq \limsup _{r} q_{r}<\infty$, then

$$
\left\{A_{k}\right\} \stackrel{W S_{\theta}^{L}}{\sim}\left\{B_{k}\right\}=\left\{A_{k}\right\} \stackrel{W S_{L}}{\sim}\left\{B_{k}\right\}
$$

Proof. This is an immediate consequence of Theorems 16 and 17.

\section{References}

[1] R. F. Patterson, "On asymptotically statistical equivalent sequences," Demonstratio Mathematica, vol. 36, no. 1, pp. 149153, 2003.

[2] R. F. Patterson and E. Savaş, "On asymptotically lacunary statistically equivalent sequences," Thai Journal of Mathematics, vol. 4, pp. 267-272, 2006.

[3] M. S. Marouf, "Asymptotic equivalence and summability," International Journal of Mathematics and Mathematical Sciences, vol. 16, no. 4, pp. 755-762, 1993.

[4] J. A. Fridy, "On statistical convergence," Analysis, vol. 5, no. 4, pp. 301-313, 1985.

[5] M. Baronti and P. L. Papini, "Convergence of sequences of sets," in Methods of Functional Analysis in Approximation Theory, vol. 76, pp. 135-155, Birkhäuser, Basel, Switzerland, 1986.

[6] F. Nuray and B. E. Rhoades, "Statistical convergence of sequences of sets," Fasciculi Mathematici, vol. 49, pp. 87-99, 2012.

[7] U. Ulusu and F. Nuray, "Lacunary statistical convergence of sequence of sets," Progress in Applied Mathematics, vol. 4, no. 2, pp. 99-109, 2012.

This completes the proof.

Combining Theorems 16 and 17 we have the following. 


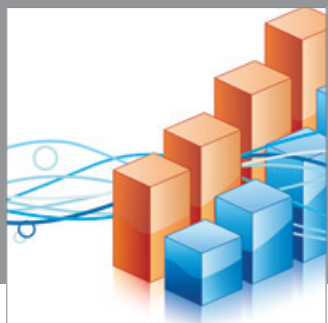

Advances in

Operations Research

mansans

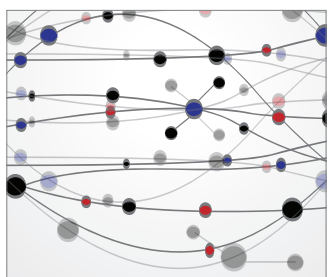

The Scientific World Journal
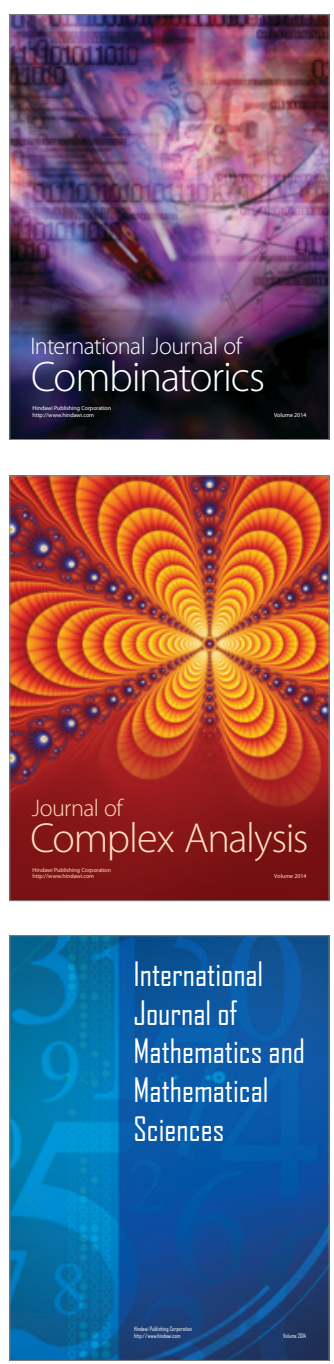
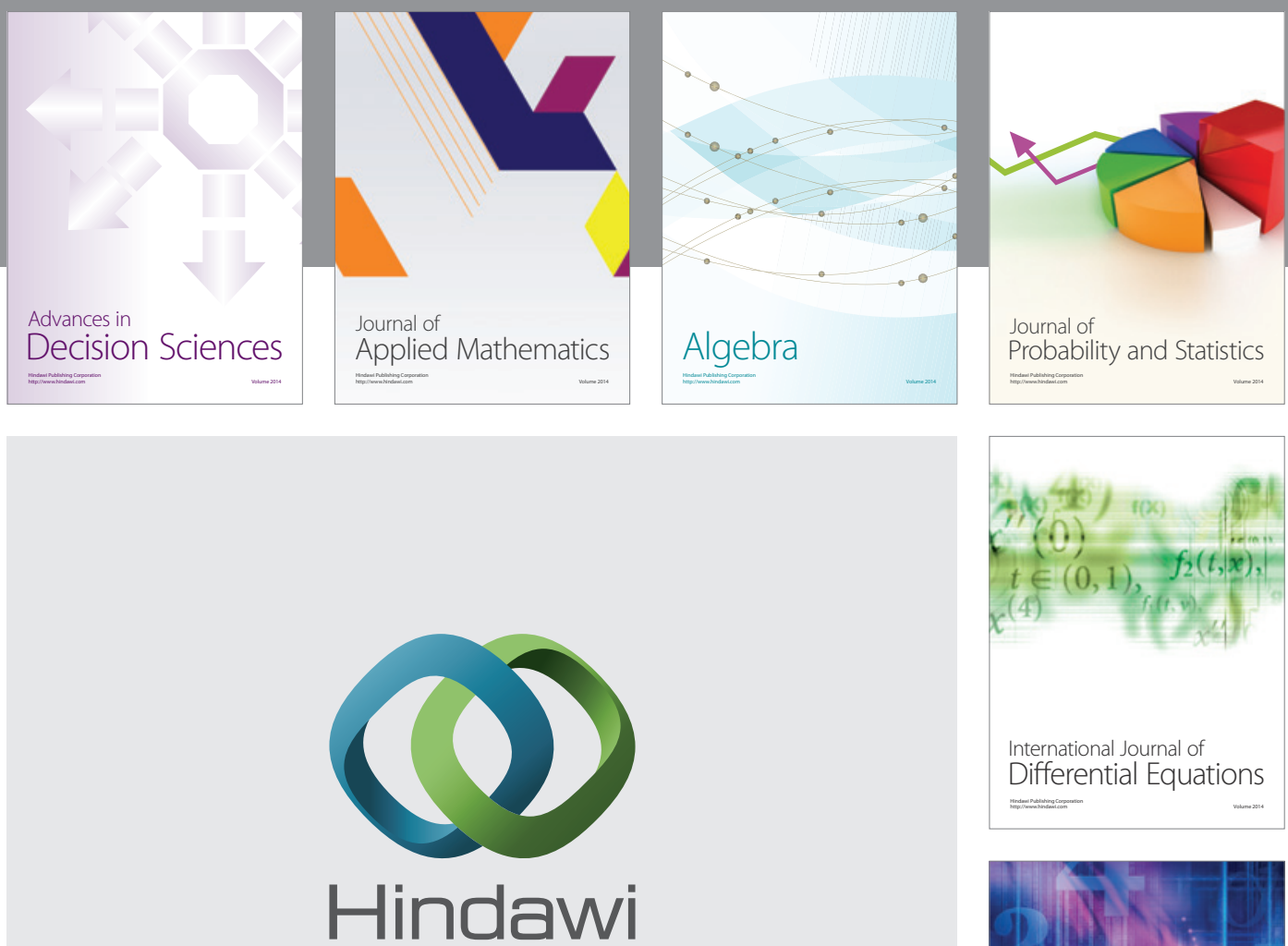

Submit your manuscripts at http://www.hindawi.com
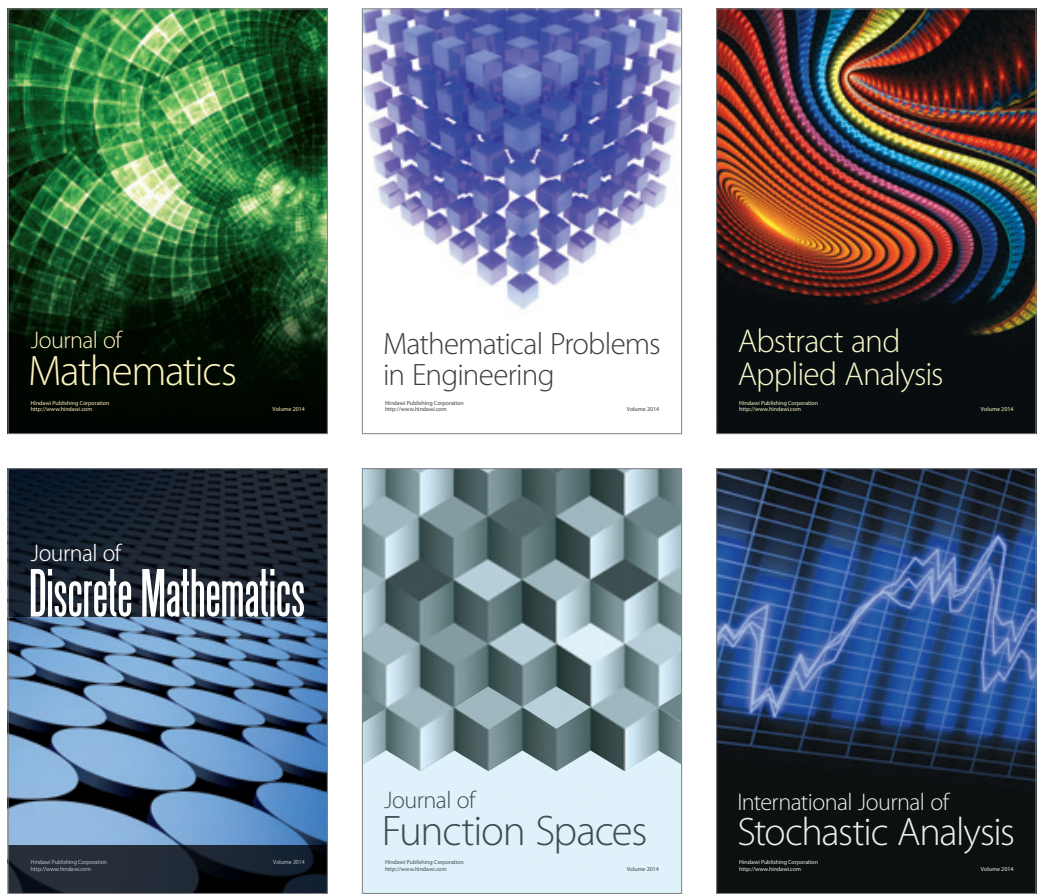

Journal of

Function Spaces

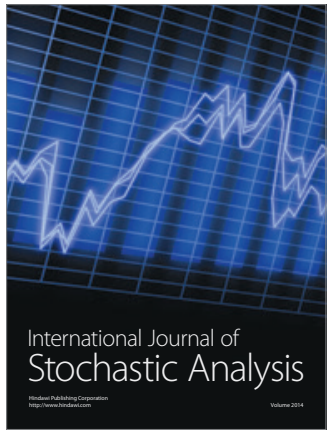

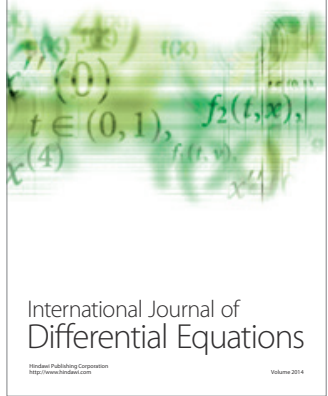
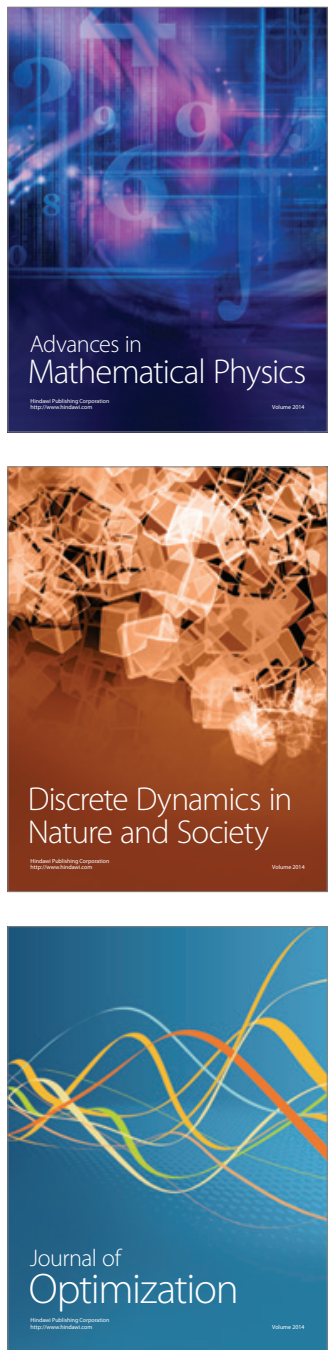